\title{
145. Conductive MgO under High Pressure
}

\author{
By Naoto KaWAI and Akio NishiYama \\ Department of Physics, Faculty of Engineering Science, \\ Osaka University, Toyonaka, Osaka \\ (Comm. by Tei-ichi Iто, м. J. A., Oct. 12, 1974)
}

$\mathrm{MgO}$ is a typical insulator with a large energy gap and electrical resistance at ordinary pressure and temperature. It, nevertheless, has long been believed to become metallic, when submitted to a super high pressure of the order of several Mb. Such a state is certainly occurring deep within the planets as Bernal ${ }^{1)}$ and Ramsey ${ }^{2)}$ have propounded.

In order to provide it in the laboratory at room temperature, a single crystal of $\mathrm{MgO}$ with purity of $99.99 \%$ is carefully compressed in a spherical pressure vessel made up of two stages. ${ }^{3)}$ In this vessel one can measure the resistance (electrical) continuously while pressure around the specimen is being elevated. Change of resistance thus obtained is shown in Fig. 1. When the load upon the vessel is elevated slowly through 980 ton, the high resistivity disappears almost instantaneously. It decreases from $1.9 M \Omega$ to $1 \Omega$ or less by 6 orders of magnitude. Above this pressure $\mathrm{MgO}$ remains to have the specific resistance not greater than $0.004 \Omega \mathrm{cm}$.

The high resistivity reappears at 830 ton in the course of releasing pressure. The conductive state is only stable under pressures and can not unfortunately be taken out of the vessel.

As reported recently by the present authors, $\mathrm{SiO}_{2}$ becomes to be a similar state within the same high pressure vessel. ${ }^{4}$ It undergoes the transition at 685 ton which is approximately two third of load required for the conductive $\mathrm{MgO}$ as shown in the diagram.

Although pressure calibration is hardly accomplished as yet in our experiment, each conductive phase occurs at pressure much higher than that of conductive GaP $(0.5 \mathrm{Mb}) .^{5)}$

\section{References}

1) Bernal, J. D.: Discussion Observatory, 59, 268 (1936).

2) Ramsey, W. H.: Monthly Notes Roy. Astron. Soc., 5, 409 (1949).

3) Kawai, N., Togaya, M., and Onodera, A.: Proc. Japan Acad., 49, 623 (1973).

4) Kawai, N., and Nishiyama, A.: Proc. Japan Acad., 50, 72 (1974).

5) Onodera, A., Kawai, N., Ishizaki, K., and Spain, L.: Solid State Commun., 14, 803 (1974). 


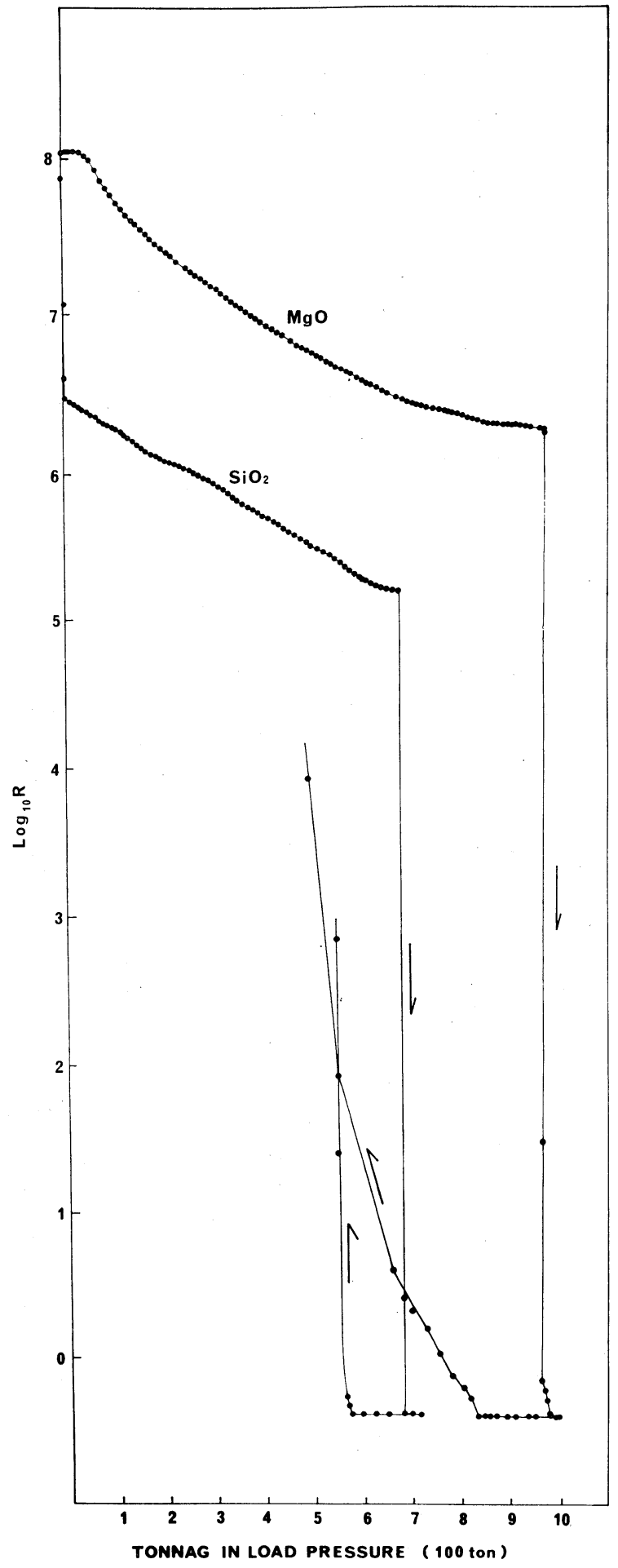

Fig. 1 